\title{
Implementing Holiday Provision Programmes: A Qualitative Investigation of the Experiences of Senior Stakeholders
}

\author{
Emily Mann', Clara Widdison'2, Margaret Anne Defeyter ${ }^{1}$ \\ ${ }^{1}$ Department of Social Work, Education and Community Wellbeing, Northumbria University, Newcastle upon Tyne, UK \\ ${ }^{2}$ Mayor's Fund for London, City Hall, London, UK \\ Email:emily.k.mann@northumbria.ac.uk,greta.defeyter@northumbria.ac.uk
}

How to cite this paper: Mann, E., Widdison, C., \& Defeyter, M. A. (2020). Implementing Holiday Provision Programmes: A Qualitative Investigation of the Experiences of Senior Stakeholders. Open Journal of Social Sciences, 8, 286-302.

https://doi.org/10.4236/jss.2020.87023

Received: June 22, 2020

Accepted: July 24, 2020

Published: July 27, 2020

Copyright $\odot 2020$ by author(s) and Scientific Research Publishing Inc. This work is licensed under the Creative Commons Attribution International License (CC BY 4.0).

http://creativecommons.org/licenses/by/4.0/ (c) (i) Open Access

\begin{abstract}
Holiday provision is a grassroots response to support low-income families during the school holidays with the provision of free food and activities. This qualitative study investigates the views of senior stakeholders $(\mathrm{N}=15)$ who are responsible for facilitating or implementing programmes of holiday provision to determine the need for holiday provision, examples of best practice for delivering programmes of holiday provision and barriers for effective delivery. The findings identified a need for holiday provision as a result of cuts to welfare provision and local authority services which have increased pressures on household budgets. Senior stakeholders advocated a collaborative and flexible model of holiday provision and identified the need to utilize and develop existing community assets to deliver this provision, Yet, senior stakeholders acknowledged multiple barriers of delivery related to cost, sustainability and organizational capacity and, in the absence of a strategic response and sustained funding by national, regional and local governments, there are questions of whether this type of approach truly addresses and targets all of the most vulnerable in society.
\end{abstract}

\section{Keywords}

School Holidays, Holiday Provision, Holiday Clubs, Food Insecurity, Child

\section{Introduction}

Holiday provision programmes are a grassroots response to the lack of statutory provision to support the nutritional and developmental needs of low-income children during the school holidays (Defeyter et al., 2019; Graham et al., 2016; 
Stretesky et al., 2020). Practitioners and academics generally refer to "holiday provision" as the provision of free food and activities to children living in deprived communities. During school term time, there exists school-based food programmes to support the nutritional needs of children and these vary across the devolved nations. Across all four nations (England, Scotland, Wales and Northern Ireland) a means tested benefit of Free School Meals (FSM) is provided to school-aged children, subsidized school milk is available to schools, and all food served in schools must comply to School Food Standards, although these standards are specific to each nation. In addition, Universal Infant FSM is available to children in England and Scotland during their first three years of primary school and, in England, all children, aged 4 to 6 years, are entitled to a free piece of fruit and vegetable each day under the School Fruit and Vegetable Scheme. Free breakfast provision is offered as a universal entitlement to primary aged children in Wales and as a voluntary provision with the National Schools Breakfast Programme in England and Extended Schools Programme in Northern Ireland (Food Foundation, 2019). These breakfast clubs provide the opportunity for children to consume a healthy breakfast at the start of the school day and support positive breakfast habits (Adolphus et al., 2019; Harvey-Golding et al., 2015). Despite the existence of these school-based programmes during term time, there is no universal state provision during the school holidays and it is evident that parents may experience increased financial pressure when these programmes are not available (Gooseman et al., 2019; Ridge, 2002). Whilst families may not be food insecure during term time, this risk may increase when some of the "safety nets" that are available during school term time are absent during the school holidays. Moreover, the need for holiday provision has increased as a result of recent reforms to the welfare and benefits system and cuts to local authority budgets (Defeyter et al., 2019). In the UK, families have faced a decade of austerity and welfare reform against a backdrop of rising living costs and low-paid employment. Thus, there is a risk of children experiencing "holiday hunger", a term used by politicians and the media to describe the financial hardship for families and the inadequate supply of healthy food during the school holidays (Defeyter et al., 2019; Graham et al., 2016). A report published by Feeding Britain (2017) estimates that three million children are at risk of experiencing holiday hunger: one million children from families receiving benefits and a further two million children from families experiencing in-work poverty (Forsey, 2017). In response to the risk of families experiencing holiday hunger, hundreds of holiday clubs have established in deprived communities across the UK with the aim of providing food to children at risk of experiencing food insecurity during the school holidays (Forsey, 2017; Graham et al., 2016; Mann et al., 2018). Nevertheless, low-income families face not only the risk of food insecurity during the school holidays but also experience the challenge of sourcing and accessing adequate and affordable childcare and play provision (Cottell \& Fiaferana, 2018). Thus, holiday clubs provide not only food provision but a range of 
enrichment and physical activities to children (Forsey, 2017).

In the absence of any statutory provision to govern the implementation and delivery of holiday provision, local authorities and the third sector have established programmes of holiday provision, albeit in a piecemeal and fragmented manner (Forsey, 2017; Mann et al., 2018). Holiday clubs are becoming more prevalent (Mann \& Defeyter, 2017) and through this organic development of holiday provision, there exists different models of holiday provision delivery: individual holiday clubs; small networks of schools and community groups delivering holiday provision and receiving grants from local authorities, foundations or housing associations; and larger networks of holiday provision clubs that are supplied with food and funds from charities, local authorities or regional government (Forsey, 2017). More recently central and regional governments have pledged funding for holiday provision programmes: in 2019 the Department for Education provided funding of $£ 9 \mathrm{~m}$ to programmes across 11 geographic areas of England to provide food and activities to 50,000 children through the Holiday Activities and Food Programme; the Scottish Government announced a fund of $£ 3 \mathrm{~m}$ to support affordable after-school and holiday childcare for low-income families; and the Welsh Government provided funding of $£ 100,000$ to pilot holiday clubs across 13 local authorities in Wales. Despite these funding initiatives, holiday provision is not universal and is unevenly distributed among disadvantaged communities and, as yet, there is no best practice guide on what works best in holiday club settings (Mann et al., 2018).

Previous academic research has investigated the benefits and issues of holiday provision from the views of staff delivering holiday provision and attendees of holiday clubs, and identified outcomes in terms of health and wellbeing for children as well as parents, staff and volunteers (Defeyter et al., 2015; Graham et al., 2016; Holley et al., 2019; Morgan et al., 2019). Moreover, recent research identified that holiday clubs relied upon networks and connections with other civil society organizations to deliver holiday provision (Stretesky et al., 2020). Nevertheless, there is a gap in the literature on the implementation of holiday provision and the adaption and fidelity of providing food provision within community and school based settings (Graham et al., 2016; Holley et al., 2019; Morgan et al., 2019). As the development of holiday clubs continues, there is a need to examine the views of senior stakeholders responsible for facilitating and implementing holiday provision. Whilst there are different models of holiday club delivery, operated by a range of organizations, they have a common purpose of delivering food and activities to children from deprived communities during the school holidays. Thus, the purpose of this current study was to address gaps in the literature on the implementation of holiday provision and aimed to answer the following three research questions: 1) What are the views and experiences of senior stakeholders regarding the need for holiday provision?; 2) What are the views and experiences of senior stakeholders in terms of good practice?; and 3) What are the views and experiences of senior stakeholders regarding the main 


\section{barriers to effective delivery?}

\section{Materials and Methods}

\subsection{Approach}

The current study adopted a qualitative, semi-structured interview approach to determine the views of senior stakeholders responsible for implementing and supporting holiday provision. Semi-structured interviews were considered the appropriate method of data collection for this sample and previously used in qualitative research examining the views of stakeholders implementing school breakfast clubs (Harvey-Golding et al., 2016). Full ethical approval for this study was obtained by Northumbria University's Faculty of Health and Life Sciences Ethics Committee.

\subsection{Procedure}

A purposive sampling strategy was adopted to sample between 12 and 18 participants to generate adequate, rich and multifaceted data from a wide sample of senior stakeholders and to ensure variety in the resulting sample. Senior stakeholders representing national, regional and local government, funding organizations and third sector organizations, responsible for implementing or supporting holiday provision programmes, were invited to participate.

Fifteen participants ( 4 male and 11 female) agreed to participate in the current study. The participants were recruited from across England. They represented senior leadership positions within their organizations, working with frontline services, and were responsible for implementing and delivering programmes of holiday provision within their region. In addition policymakers, from local, regional and national governments, with an interest in food security agreed to participate in this study. A summary of the roles of the participants is illustrated in Table 1.

All participants were supplied with written information about this research study and a consent form. Fully informed, written consent, was received from

Table 1. Summary of roles of participants.

\begin{tabular}{cc}
\hline & N \\
\hline Senior Stakeholders: & 5 \\
Local authorities (Managers) & 3 \\
Housing associations (Managers) & 3 \\
Public Health England (Manager) & 1 \\
\hline Policymakers: & Central Government (MP) \\
Regional Government (Assembly Member) & 1 \\
Local Government (Councillor) & 1 \\
\hline
\end{tabular}


participants prior to the interviews taking place. In addition to the written information distributed to participants, a verbal explanation of the purpose of the study, participants right to withdraw, and how their data would be handled was reiterated to participants prior to the commencement of each interview.

All interviews were audio recorded and took place either face-to-face $(\mathrm{N}=11)$ or via telephone $(\mathrm{N}=4)$. The face-to-face interviews were held in the participants' workplace. The decision to undertake telephone interviews was a pragmatic choice to reduce the burden on participants, encourage participation in this study and as a result of some participants for this study being widely dispersed geographically. The average length of an interview was 35 minutes.

\subsection{Analysis}

The interviews were listened to in their entirety before they were transcribed verbatim for subsequent thematic analysis. The transcripts were coded and analyzed in accordance with guidelines on the process of thematic analysis (Braun \& Clarke, 2006). As there currently exists no published theoretical framework for holiday provision, an inductive and deductive approach was adopted to analyze the data and answer the research questions. The codes were compared across transcripts, reduced and further refined; these codes were grouped into categories based on similarity of content, and themes were developed around categories. This analytical process took place in parallel with interviews and further theoretical sampling was undertaken until no new themes emerged from the data. Further interviews were held with a senior stakeholder representing a housing association and a policymaker from regional government. Additional sampling also tested the properties of the categories and themes. Whilst stakeholders' views of holiday club provision varied depending upon the role of their organization, and their responsibility for implementing or delivering holiday provision, key themes encompassing the range of views emerged from these interviews. The final sample size was determined by the adequacy of the richness and complexity of the data for addressing the three research questions (Braun \& Clarke, 2019).

\section{Results}

Stakeholders reflected on their knowledge and experience of advocating and implementing holiday provision programmes and shared their views on the need for holiday provision, examples of best practice and barriers for implementing and delivering holiday provision. A summary of themes identified by participants is presented together with codes and example quotes in Table 2.

\subsection{Need for Holiday Provision}

Four themes were identified from interviews with stakeholders regarding the need for holiday provision: financial hardship; "struggling" parents; play and childcare provision; and isolation. 
Table 2. Summary of themes, codes and examples quotes.

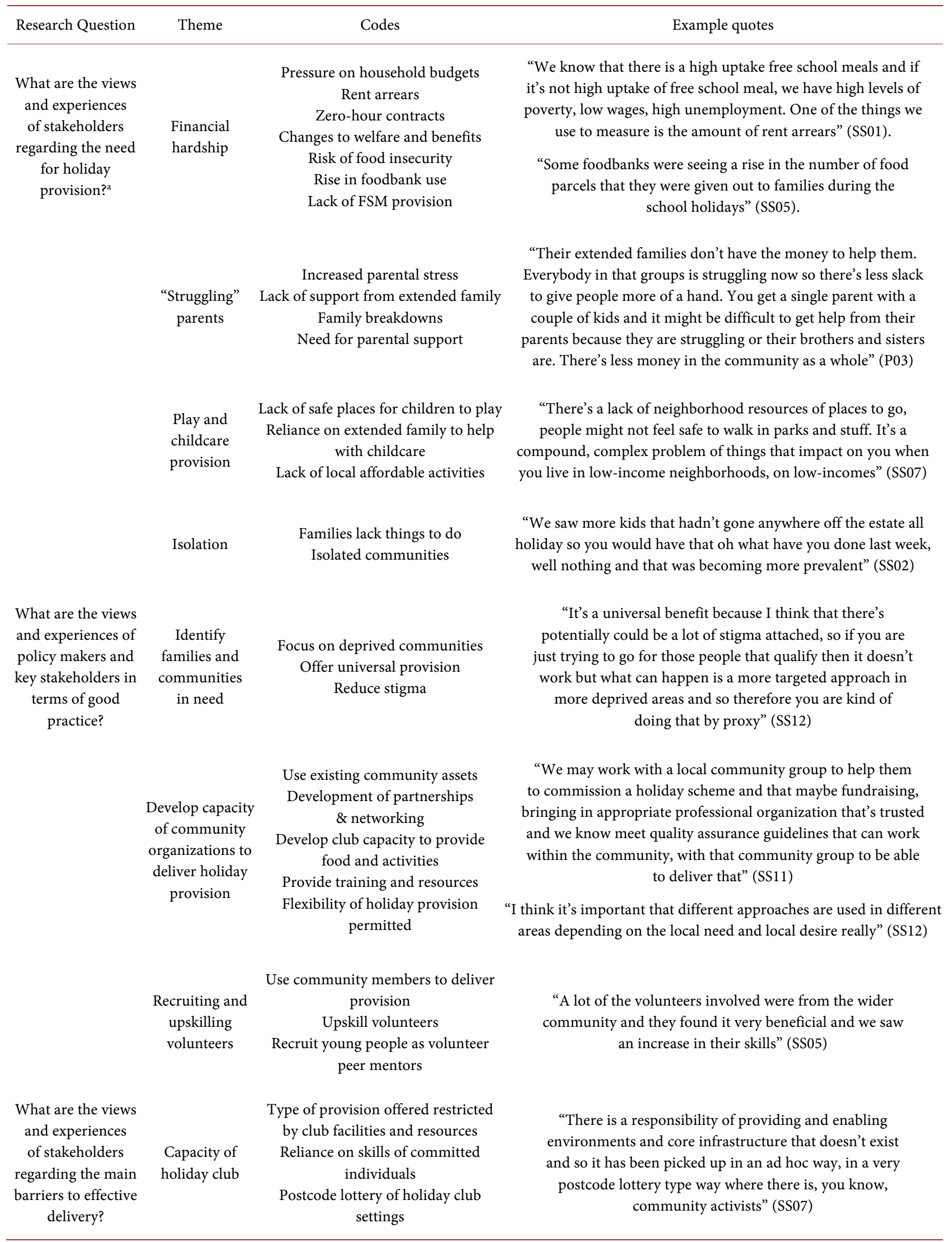




\section{Continued}

Role of local authorities \& government
Hard to reach families

Families with disabilities BME communities Variations in attendance rates

Co-ordinate provision Funding Governance of food standards
"We have probably got high numbers of families where they are in high need but they traditionally will just not access services. We are looking at ways to encourage them and advocate for them" (SSO4)

"I think it should be a partnership with the GLA, the Mayor's Fund obviously are doing stuff, there's quite a few charities involved in providing youth activities. So, I think my concern is less about who delivers it then making sure that somebody has a coordinating role, whether it's um the boroughs or whether it's through the GLA to make sure that any child who needs to have this holiday provision" (P02)

"If there is any statutory money then I think standards do need to apply that apply to school food in the same sort of way" (P01)

"We very much believe is that there needs to be a long-term policy solution to this and we would advocate the government spends money on this area to tackle this problem" (SS09)

Stakeholders reflected that low-income families, living in deprived communities, experienced financial hardship and increased pressures on household budgets during the school holidays. Stakeholders felt that pressures on household budgets were exacerbated by changes to the welfare system and by families reliant on low-paid jobs and unpredictable working arrangements i.e. zero-hour contracts. Stakeholders referred to anecdotal evidence regarding changes to welfare provision and the ensuing impact on low-income households; they used national and local datasets and liaised with partner agencies to identify communities and households with high levels of deprivation and in need of further provision and support. Given the financial hardship experienced by families, stakeholders reflected on the risk of families experiencing food insecurity and expressed their concern for families who rely on FSM provision during term time and the lack of this state provision during the school holidays. Moreover, stakeholders highlighted the rise in foodbank use by families during the school holidays, demonstrating a need for families to rely on the support of emergency food aid and the risk of children experiencing hunger and malnutrition during the school holidays. Thus, stakeholders emphasized the importance of delivering food provision at holiday clubs as they believed that the holiday club meal may be the only meal for a child that day.

Consequently, stakeholders perceived parents to be not only "struggling" to feed their families but also finding it difficult to cope with the stress of parenting during the school holidays and the subsequent impact on family relationships. Stakeholders reflected on changes to informal support structures available to low-income families. In the past, parents relied on the support from their extended family to help them to maintain their work or caring commitments during the school holidays. However, stakeholders identified that these support networks were no longer available due to increased financial pressures on other 
family members. Consequently, there is an increasing need for other support structures to be available for families within their communities.

An additional theme identified by stakeholders is the lack of adequate and affordable childcare facilities and the lack of safe places for children to play within their communities. Stakeholders discussed how recent cuts to local authority budgets affected the availability of childcare and youth provision which families had previously relied upon during the school holidays. Furthermore, stakeholders identified perceived barriers which exist within communities preventing families from accessing provision within neighboring communities. Consequently, stakeholders recognized the risk of families and communities experiencing social isolation as a result of a lack of investment in the local services and the further challenge for households to access local provision within their communities or neighboring communities.

\subsection{Examples of Good Practice of Delivering Holiday Provision}

In the absence of any statutory provisions or national guidance for implementing holiday provision, stakeholders reflected on their role or contribution towards developing a program of holiday provision within their locality. Three themes were identified in the interviews with stakeholders regarding their views of good practice of implementing and delivering holiday provision: identify families and communities in need; develop capacity of community organizations to deliver holiday provision; and recruiting and upskilling volunteers.

Stakeholders highlighted that programmes of holiday provision need to be targeted and located within deprived communities to ensure they are accessible to the families in need. Nevertheless, all stakeholders supported universal provision, with open access to all families within the community. Stakeholders reflected on how universal provision prevented families from experiencing stigma or perceiving holiday provision as a feeding scheme. Thus, stakeholders identified and targeted the most disadvantaged communities and supported community organizations and schools to establish holiday clubs within their region. Moreover, to help recruitment and target families most in need, some stakeholders advocated working with agencies such as children centers, family support workers and social services.

Stakeholders highlighted the importance of utilizing existing community assets and identified a variety of schools and community organizations to deliver holiday provision. Nevertheless, to equip these organizations and schools with adequate skills and resources to prepare and serve meals and deliver a range of activities, stakeholders identified the need to build capacity of these organizations. One means of building capacity, highlighted by stakeholders, was to develop networks and partnerships across the public, private and third sector organizations. The development of networks and partnerships not only helped stakeholders to identify examples of best practices but provided support to holiday clubs with delivering aspects of the provision i.e. providing grants, donating 
goods and services or delivering activities. Stakeholders sought to develop relationships and partnerships across the community with a range of organizations, agencies and private companies including community groups, churches, charities, local businesses, children's centers, council departments and Public Health England. Interestingly, stakeholders recognized additional benefits of these partnerships as a means for these partner organizations and agencies to develop and enhance their relationship within communities. Stakeholders highlighted that a degree of flexibility or tailoring of holiday provision was permitted by holiday clubs. Thus, schools and community organizations could adapt their holiday clubs depending on the needs of their community and the resources and assets available to them including the skills and availability of staff and volunteers and the partnerships they had fostered with partner organizations.

The final theme discussed by stakeholders was recruiting and upskilling volunteers to support the delivery of holiday provision. Stakeholders reflected on the benefits of using community members to participate in delivering holiday provision as volunteers. One participant discussed how holiday provision provided community members with an opportunity to participate in short term voluntary work without the pressure of long-term commitment:

"People are putting their hand up to volunteer, even if it s just volunteering for the summer holidays, it's actually a good thing and you are not signing on the dotted line forever and that has built confidence with people" (SS02).

Moreover, stakeholders reflected on how volunteers acquired new skills and developed confidence from their involvement in holiday provision and from undertaking training, thus enhancing their employment prospects.

\subsection{Barriers to Effective Delivery}

While all stakeholders positively viewed holiday provision and identified tangible benefits for children, their families and communities, they identified three themes on the key barriers of effective delivery of holiday provision: capacity of holiday club; attendance; and the role of local authorities and government.

Firstly, the type of provision offered by schools and community organizations at their holiday clubs is restricted by their access to facilities and resources. Whilst holiday clubs have the flexibility to offer provision based on their resources and capacity to deliver, this has led to variation in the type and frequency of provision offered. Moreover, stakeholders reflected on the challenge of engaging and recruiting schools and community groups to participate in their program. Whilst stakeholders identified disadvantaged communities and offered support to schools and community organizations within these communities to establish holiday clubs and deliver holiday provision, their programmes of holiday provision were only located in those neighborhoods where organizations had the capacity to deliver the provision. Thus, illustrating the fragmented offering of holiday provision resulting from the lack of statutory provision. 
A second theme highlighted by stakeholders was the issue of attendance at holiday clubs and variation in attendance rates. Whilst the majority of stakeholders supported a universal provision, they reflected on whether their holiday provision targeted and attracted those families most in need of support during the school holidays. Moreover, stakeholders cited that their programmes lacked the capacity to assess the demographics of families accessing their programmes of holiday provision. Nonetheless, they anticipated that as their programme operated within disadvantaged communities they were, by proxy, targeting families most in need. Still, stakeholders in North East England acknowledged that, despite the universal provision, sections of the community, in particular families with disabilities and black and minority ethnic groups, were underrepresented within their programmes of holiday provision. Consequently, stakeholders recognized limitations to the universal offering of this provision and how this provision was not as far-reaching as originally anticipated, raising the issue of the inclusivity of this type of provision. Stakeholders reflected that closer partnerships with schools, social services and family support workers would help to target those families most in need. Furthermore, some programmes of holiday provision specifically targeted their provision to primary school aged children and therefore failed to address the needs of the youngest or oldest children within their community.

The final theme of barrier for implementing effective provision focused on the role of local authorities and governments. In the absence of any statutory guidelines or core infrastructure directed by national government to shape holiday provision, stakeholders reflected on how programmes of holiday provision had developed in an "ad hoc" way. Stakeholders supported a greater role of central, regional and local governments to enable effective delivery of holiday provision. They suggested that national government should play a greater role in supporting holiday provision through funding and regulation. Stakeholders favored the implementation of statutory holiday provision supported by state funding. Furthermore, stakeholders highlighted that, alongside statutory financial support for holiday provision, there is a need for central government to introduce legislation to ensure all food served at holiday provision is healthy and nutritious, and in alignment with School Food Standards. Moreover, stakeholders highlighted the need for further involvement of local government to support holiday provision. They suggested that local authorities should develop a strategic response, provide a framework for holiday provision within their region and assume a more pivotal role in coordinating holiday provision within their region. In addition, it is envisaged that local authorities would be able to further develop partnerships across public and private organizations to harness links between organizations and facilitate the delivery of provision within their region. Thus, stakeholders identified a greater role for central and regional governments and local authorities to expand the reach of holiday provision and ensure that holiday provision is founded on a more sustainable model. 


\section{Discussion}

The aim of this current study was to examine the views of senior stakeholders responsible for facilitating and implementing programmes of holiday provision and to investigate the need for holiday provision, identify examples of best practice and examine barriers of effective delivery.

In the current study, stakeholders reflected on the impact of the recent reforms to welfare and cuts to local authority budgets and identified a need for holiday provision: to support families experiencing financial hardship; alleviate the risk of children and their parents experiencing food insecurity; and lessen the risk of families becoming isolated during the school holidays. These findings support previous research conducted by Graham et al. (2016) of the views of holiday club staff. In addition to the hardship experienced by families, the findings from this study also identified the need for affordable and accessible play and childcare provision resulting from cuts to youth provision and the lack of safe places for children to play in their neighborhoods.

Stakeholders recognized that school holidays can increase pressure on household budgets due to the increased costs of entertaining children, childcare provision and, for families who rely on term time FSM provision, the additional cost of feeding their children. With the increased demands on household budgets, stakeholders drew on their experiences of working with frontline services and acknowledged that parents struggle to afford food and/or provide their children with a good quality nutritious diet. Whereas parents may have previously relied on support from their extended family, participants suggested that, under austerity, family members are no longer able to provide that assistance. Given the increased financial pressures, participants identified that low-income households are at risk of experiencing food insecurity during the school holidays and there is a need to support families against this risk. Stakeholders identified that parents were "struggling" during the school holidays as a result of the stress of financial hardships and therefore, the ability to parent is made increasingly difficult (La Placa \& Corlyon, 2016). In addition to the material disadvantages of living in low-income households, participants reflected that low-income parents are more likely to experience non-material disadvantages which can disrupt the ability to parent such as relationship difficulties. These findings are in line with other studies on parenting in poverty (La Placa \& Corlyon, 2016) and demonstrates the need for additional support for families during the school holidays.

A report on the impact of welfare reform on communities in the UK highlighted that the poorest local authorities have been hit hardest by welfare reform and there exists a disproportionate impact of welfare reforms on low-income families with dependent children (Beatty \& Fothergill, 2016). Furthermore, whilst local authorities have attempted to protect frontline services, this has not always been possible and as result of recent cuts to local authority budgets, youth clubs, libraries and children centers have closed or reduced their opening times (Hastings et al., 2015). In addition to the cuts in local youth and play provision, 
traditionally provided by local authorities, stakeholders highlighted a lack of affordable childcare provision for low-income families during the school holidays. This finding is in keeping with a recent study, which identified a lack of affordable holiday clubs and a shortage of childcare across some regions of the UK (Cottell \& Fiaferana, 2018). It is evident that the government has pursued a policy of encouraging parents into employment whilst reducing their welfare entitlements. However, a lack of available and affordable childcare highlights shortcomings with this policy and the accompanying challenges for working families.

In the absence of statutory guidelines, stakeholders identified examples of good practice to facilitate and implement programmes of holiday provision. As a result of the aforementioned cuts to local authority budgets, stakeholders identified and targeted the most disadvantaged communities within their region for their programmes of holiday provision. To reach the most marginalized and vulnerable families they supported a universal approach to holiday provision, as opposed to a targeted method of attracting families, to avoid stigma which has been associated with food programmes and foodbanks (Garthwaite et al., 2015) and prevent holiday provision from being seen as a feeding programmes for poor families.

Stakeholders advocated a collaborative and flexible model of holiday provision and identified the need to utilize existing community assets and build the capacity of schools and community organizations to deliver this provision. The capacity of clubs was enhanced through developing partnerships, providing seed funding and offering training and resources. To deliver food provision and a range of activities, stakeholders identified a need to develop partnerships with a range of public, private and third sector organizations to support holiday clubs. Research conducted by Skinner et al. (2008) demonstrates that by fostering a diverse range of partners helps to contribute to the long-term viability, funding and community engagement of grassroots initiatives (Skinner et al., 2008). Thus, this approach ensures that clubs are not reliant on one partner or funding group. Stakeholders provide a range of resources and training to upskill staff and build capacity of an organization, specifically with the delivery of food provision. An additional benefit is the flexibility of the model which enables schools and community organizations to have autonomy over the type of holiday provision they deliver such as the setting of the holiday clubs, operating times, type of food served, and activities provided. Therefore, encouraging a range of community organizations and schools to establish holiday clubs. Whilst there are benefits to a flexible model of holiday provision, in the absence of a universal governance structure to monitor quality assurance, it raises the question of whether all holiday clubs have the resources and skills to provide healthy nutritious meals and address the issue of holiday food insecurity.

Stakeholders recognized the benefit of volunteers to help deliver their programme of holiday provision and reflected on the positive outcomes for volunteers participating in holiday provision including enhancing skills and devel- 
oping confidence. Previous research illustrates that residents of disadvantaged communities can experience a range of positive psychological, social and economic benefits from their participation and, in addition, improve the social capital of deprived communities (Hanson et al., 2016; Messias et al., 2005). A further benefit of this type of volunteering is the short-term commitment and the fact that community members can participate on a project by project basis. Whilst there are perceived benefits for community members to volunteer in holiday provision, there are also advantages for holiday clubs to utilize community members in delivering this provision. Stakeholders reflected on how volunteers provided additional support to delivery partners through their knowledge of the community and by identifying and targeting those in families in need of support. Stakeholders recognized that as volunteers are upskilled, they are able to use these skills and experience to secure employment which, in turn, demonstrates a need to invest in the cycle of recruiting and training new volunteers into these roles.

Whilst stakeholders identified examples of good practice, they acknowledged multiple barriers of delivering holiday provision related to cost, sustainability and organizational capacity. Moreover, it is important to recognize the barriers of implementing food security interventions for the development of future programmes (Matthews et al., 2012). The type of holiday provision offered is restricted by the capacity of schools and community organizations to deliver food provision and activities and the facilities and resources available at holiday clubs. Stakeholders highlighted the need to develop the capacity of school and community organizations to deliver holiday provision by developing partnerships, it is evident from the interviews that there is a reliance on skills of committed individuals. Previous research demonstrates the dependency on individual volunteers and staff to broker relationships and acquire resources for the benefit of the holiday club and its participants (Stretesky et al., 2020). Thus, there is fragility in the relationships between holiday clubs and partner agencies and the need to embed support for holiday provision within organizational structure.

Stakeholders identified challenges around attendance and reaching families in need. There are gaps in the provision where the recruitment of schools or community organizations was not possible. This finding further highlights that in the absence of statutory provision, the location of holiday provision is fragmented. Furthermore, there is a lack of data on families accessing the provision which makes it difficult to measure whether the provision is reaching the most marginalized families. Previous research demonstrates that active recruitment methods to engage hard-to-reach populations are more effective than a passive approach (Chaskin, 2009; Loopstra, 2018). Although a universal approach is advocated and non-discriminatory in terms of household income of families, it is selective in terms of the age of the child and stakeholders recognized that black and mixed ethnic groups as well as families with special educational needs and disabilities were also underrepresented. Moreover, the issues highlighted in this paper for 
the need of holiday provision i.e. financial hardship and risk of families experiencing food insecurity are not generated at a local level and therefore, solutions are required for these structural problems by changes to welfare policy. Nevertheless a lot can be done to support low-income families at the local level through holiday provision by developing the capacity of organizations and making disadvantaged communities more supportive environments for families (Kneafsey et al., 2017).

Finally, there is a need for more support from government and local authorities in terms of funding, governance of food standards and coordination of provision. Stakeholders cited a need for guidance to ensure programmes of holiday provision help to reduce food insecurity. As Kneafsey et al. (2017) argues, whilst charity-led interventions can contribute to capacity building for food justice, there are limitations with this type of intervention: "they are often unable to reach the most marginalized communities: their work is often piecemeal, depending on whether they are able to attract funding or not. Charity-led food initiatives, therefore, need to be designed and properly funded to target people most affected by food injustice." (Kneafsey et al., 2017: p. 631). Thus, findings from this study demonstrate that sustainable holiday provision requires cooperation, partnerships and networks of collaboration between community organizations, community members, government as well as the private sector (Dale \& Newman, 2008; Stretesky et al., 2020). Building the capacity of community organizations delivering holiday provision can be achieved through strategies such as developing leadership skills of community members, organizational development to improve their existing services or to include additional services and/or provision, and improving organizational infrastructure to strengthen the links between organizations and agencies (Kneafsey et al., 2017).

The current study expands upon current qualitative research in the field and provides a unique and insightful contribution into the need, implementation and delivery of holiday provision from the perspectives of senior level stakeholders. There is increasing pressure on community organizations to respond to local need and provide additional support to low-income families during the school holidays. The current findings offer a timely contribution to the research literature in this area given the UK government announced funding to provide vouchers to children, eligible for FSM provision, during the school summer holidays in 2020 and recognized the increased financial pressures faced by families during the COVID-19 pandemic (Department for Education, 2020). Nevertheless, a sustainable, long-term funding structure, led by the UK government is required to invest in communities and build capacity of organizations to offer local holiday programmes to all vulnerable children. It is important to note the limitations of this current study as this paper reports the views of a small, albeit diverse, sample of stakeholders responsible for facilitating and delivering holiday provision. Although the need for holiday provision and examples of good practices and issues of delivering holiday provision are supported by themes in pre- 
vious research of holiday club staff (Graham et al., 2016; Holley et al., 2019; Stretesky et al., 2020), further research is necessitated, by means of a process evaluation, to gain a more comprehensive knowledge of holiday programmes in terms of implementation, fidelity, dose and reach.

\section{Conclusion}

To conclude, stakeholders identified a need for holiday programmes during the school holidays as a result of the cuts to welfare provision and local authority budgets which have increased pressures on household budgets. In the absence of statutory provision, local authorities and the third sector are implementing and delivering holiday clubs in disadvantaged communities. By building community capacity through developing human capital and organizational resources, holiday programmes can support low-income families in disadvantaged communities. Yet, there are questions of whether this type of approach truly addresses and targets the most vulnerable in society and is sustainable in the absence of a strategic response and the availability of consistent funding by national, regional and local governments.

\section{Conflicts of Interest}

The authors declare no conflicts of interest regarding the publication of this paper.

\section{References}

Adolphus, K., Lawton, C. L., \& Dye, L. (2019). Associations between Habitual School-Day Breakfast Consumption Frequency and Academic Performance in British Adolescents. Frontiers in Public Health, 7, 283. https://doi.org/10.3389/fpubh.2019.00283

Beatty, C., \& Fothergill, S. (2016). The Uneven Impact of Welfare Reform: The Financial Losses to Places and People. https://doi.org/10.21201/2016.604630

Braun, V., \& Clarke, V. (2006). Using Thematic Analysis in Psychology. Qualitative Research in Psychology, 3, 77-101. https://doi.org/10.1191/1478088706qp063oa

Braun, V., \& Clarke, V. (2019). To Saturate or Not to Saturate? Questioning Data Saturation as a Useful Concept for Thematic Analysis and Sample-Size Rationales Useful Concept for Thematic Analysis and Sample-Size Rationales. Qualitative Research in Sport, Exercise and Health. https://doi.org/10.1080/2159676X.2019.1704846

Chaskin, R. J. (2009). Building Community Capacity for Children, Youth and Families. Children Australia, 34, 31-38. https://doi.org/10.1017/S1035077200000511

Cottell, J., \& Fiaferana, K. (2018). Holiday Childcare Survey 2018. https://www.familyandchildcaretrust.org/childcare-survey-2018

Dale, A., \& Newman, L. (2008). Social Capital: A Necessary and Sufficient Condition for Sustainable Community Development? Community Development Journal, 45, 5-21. https://doi.org/10.1093/cdj/bsn028

Defeyter, M. A., Graham, P. L., \& Prince, K. (2015). A Qualitative Evaluation of Holiday Breakfast Clubs in the UK: Views of Adult Attendees, Children, and Staff. Frontiers in Public Health, 3, 199. https://doi.org/10.3389/fpubh.2015.00199 
Defeyter, M. A., Stretesky, P. B., \& Long, M. A. (2019). Holiday Hunger: The Government Must Remove the Inequalities in Children's Access to Holiday Clubs. BMJ(Online). https://blogs.bmj.com/bmj/2019/10/23/holiday-hunger-the-government-must-removethe-inequalities-in-childrens-access-to-holiday-clubs

Department for Education (2020). COVID Summer Food Fund. https://www.gov.uk/guidance/covid-summer-food-fund

Food Foundation (2019). Children's Future Food Inquiry. https://foodfoundation.org.uk/wp-content/uploads/2019/04/Childrens-Future-Food-In quiry-report.pdf

Forsey, A. (2017). Hungry Holidays: A Report on Hunger amongst Children during School Holidays. https://feedingbritain.files.wordpress.com/2015/02/hungry-holidays.pdf

Garthwaite, K. A., Collins, P. J., \& Bambra, C. (2015). Food for Thought: An Ethnographic Study of Negotiating Ill Health and Food Insecurity in a UK Foodbank. Social Science \& Medicine, 132, 38-44. https://doi.org/10.1016/j.socscimed.2015.03.019

Gooseman, A., Defeyter, M. A., \& Graham, P. L. (2019). Hunger in the Primary School Setting: Evidence, Impacts and Solutions According to School Staff in the North East of England, UK Solutions According to School Staff in the North East of England, UK. International Journal of Primary, Elementary and Early Years Education, 48, 191-203. https://doi.org/10.1080/03004279.2019.1602155

Graham, P. L., Crilley, E., Stretesky, P. B., Long, M. A., Palmer, K. J., Steinbock, E., \& Defeyter, M. A. (2016). School Holiday Food Provision in the UK: A Qualitative Investigation of Needs, Benefits, and Potential for Development. Frontiers in Public Health, 4, Article 172. https://doi.org/10.3389/fpubh.2016.00172

Hanson, K. L., Connor, L., Olson, C. M., Mills, G., Hanson, K. L., Connor, L., Olson, C. M., \& Mills, G. (2016). Household Instability and Unpredictable Earnings Hinder Coping in Households with Food Insecure Children. Journal of Poverty, 20, 464-483. https://doi.org/10.1080/10875549.2016.1141382

Harvey-Golding, L., Donkin, L. M., \& Defeyter, M. A. (2016). Universal Free School Breakfast: A Qualitative Process Evaluation According to the Perspectives of Senior Stakeholders. Frontiers in Public Health, 4, Article 161. https://doi.org/10.3389/fpubh.2016.00161

Harvey-Golding, L., Donkin, L. M., Blackledge, J., \& Defeyter, M. A. (2015). Universal Free School Breakfast: A Qualitative Model for Breakfast Behaviors. Frontiers in Public Health, 3, Article 154. https://doi.org/10.3389/fpubh.2015.00154

Hastings, A., Bailey, N., Bramley, G., Gannon, M., \& Watkins, D. (2015). The Cost of the Cuts: The Impact on Local Government and Poorer Communities. Joseph Rowntree Foundation Report (Issue March).

Holley, C. E., Mason, C., \& Haycraft, E. (2019). Opportunities and Challenges Arising from Holiday Clubs Tackling Children's Hunger in the UK: Pilot Club Leader Perspectives. Nutrients, 11, pii: E1237. https://doi.org/10.3390/nu11061237

Kneafsey, M., Owen, L., Bos, E., Broughton, K., \& Lennartsson, M. (2017). Capacity Building for Food Justice in England: The Contribution of Charity-Led Community Food Initiatives. Local Environment, 22, 621-634.

https://doi.org/10.1080/13549839.2016.1245717

La Placa, V., \& Corlyon, J. (2016). Unpacking the Relationship between Parenting and Poverty: Theory, Evidence and Policy. Social Policy and Society, 15, 11-28. https://doi.org/10.1017/S1474746415000111

Loopstra, R. (2018). Interventions to Address Household Food Insecurity in High-Income Countries. Proceedings of the Nutrition Society, 77, 1-12. 
https://doi.org/10.1017/S002966511800006X

Mann, E., \& Defeyter, G. (2017). Holiday Club Survey 2017 Preliminary Findings. http://www.frankfield.co.uk/upload/docs/Holiday\%20Club\%20Survey

Mann, E., Long, M. A., Stretesky, P. B., \& Defeyter, M. A. (2018). A Question of Justice: Are Holiday Clubs Serving the Most Deprived Communities in England? Local Environment, 23, 1008-1022. https://doi.org/10.1080/13549839.2018.1518415

Matthews, A., Brennan, G., Kelly, P., Mcadam, C., Mutrie, N., \& Foster, C. (2012). Don’t Wait for Them to Come to You, You Go to Them. A Qualitative Study of Recruitment Approaches in Community Based Walking Programmes in the UK. BMC Public Health, 12, Article No. 635. https://doi.org/10.1186/1471-2458-12-635

Messias, D. K. H., De Jong, M. K., \& McLoughlin, K. (2005). Being Involved and Making a Difference. Journal of Holistic Nursing, 23, 70-88. https://doi.org/10.1177/0898010104272023

Morgan, K., McConnon, L., Van Godwin, J., Hawkins, J., Bond, A., \& Fletcher, A. (2019). Use of the School Setting During the Summer Holidays: Mixed-Methods Evaluation of Food and Fun Clubs in Wales. Journal of School Health, 89, 829-838.

https://doi.org/10.1111/josh.12824

Ridge, T. (2002). Childhood Poverty and Social Exclusion: The Child's Perspective. Bristol: The Policy Press. https://doi.org/10.2307/j.ctt1t8986p

Skinner, J., Zakus, D. H., \& Cowell, J. (2008). Development through Sport: Building Social Capital in Disadvantaged Communities. Sport Management Review, 11, 253-275. https://doi.org/10.1016/S1441-3523(08)70112-8

Stretesky, P. B., Defeyter, M. A., Long, M. A., Sattar, Z., \& Crilley, E. (2020). Holiday Clubs as Community Organisations. Annals of the American Academy of Political and Social Science, 689, 129-148. https://doi.org/10.1177/0002716220917657 